\title{
Criterios para el tratamiento contable de derivados financieros del sector real en Colombia
}

Recibido: 25 de julio de 2013

Aprobado: 15 de octubre de 2013

Miguel Ángel Laverde Sarmiento ${ }^{1}$

Laverde, M. Á. (2013). Criterios para el tratamiento contable de derivados financieros del sector real en Colombia. Activos 21, 139-168.

Clasificación JEL: G00

\section{Resumen}

Los instrumentos financieros son cada vez más utilizados en el mundo debido a los múltiples usos que se les puede dar, sin embargo, se debe tener en cuenta que los riesgos relacionados con desvalorizaciones repentinas asociadas a los cambios de valor en el mercado y al alto precio en la inversión afectan los flujos de efectivo del inversionista y las utilidades del ejercicio; por lo tanto, los entes regulatorios se han visto en la necesidad de crear reglas y normas contables para poder contrarrestar los múltiples riesgos.

El presente artículo evalúa diferentes formas de la contabilización de derivados financieros en la normatividad colombiana, según los Principios Generales Aceptados de Contabilidad de los Estados Unidos (USGAAP, por sus siglas en inglés) y las Normas Internacionales de Estados Financieros (IFRS, por sus siglas en inglés) con el fin de encontrar la manera más adecuada de presentar la información para una correcta toma de decisiones

1 Contador público. Docente Universidad Santo Tomás. Correo electrónico: miguellaverde@usantotomas.edu.co 
contables en las empresas del sector real debido a que en las empresas financieras estas prácticas se encuentran muy bien estipuladas.

\title{
Palabras clave
}

Derivados financieros, subyacente financiero, revelación plena, subyacente energético, commodities.

Laverde, M. Á. (2013). Criteria for accountant treatment of financial derivatives from real sector in Colombia. Activos 21, 139-168.

\begin{abstract}
Financial instruments are increasingly used worldwide due to the many uses that can be given, however you should note that the risks associated with sudden impairment associated with changes in market value and the high price investment cash flows affect investor and net income; therefore regulatory agencies have seen the need to create rules and accounting rules to counter the multiple risks.

This article evaluates different ways of accounting for financial derivatives in Colombian law, according to U.S. GAAP and IFRS in order to find the most appropriate way to present the information for proper decision making in the real sector companies due to financial companies in these practices are very well set out.
\end{abstract}

\section{Keywords}

Financial Derivatives, financial underlying, full disclosure, energetic underlying, commodities. 
Laverde, M. Á. (2013). Critères pour le traitement comptable de dérivés financiers du secteur réel en Colombie. Activos 21, 139-168.

\section{Résumé}

Les instruments financiers sont utilisés de plus en plus dans le monde, du aux multiples usages possibles, en revanche, il faut tenir compte que les risques liés aux dévalorisations soudaines, associées aux changements de valeur dans le marché et le prix élevé de l'investissement, affectent le flux de trésorerie de l'investisseur et les profits de l'exercice; des lors, les entités régulatrices ont vu la nécessité de créer des règles et normes comptables qui puissent contrebalancer les multiples risques .

Le présent article évalue différentes formes de comptabilisation de dérives financiers, dans la réglementation colombienne, selon les Principes Généraux Acceptés en Comptabilité aux Etats Unis ( USGAAP, par sa sigle en anglais) et les Normes Internationales des Etats Financiers (IFRS, par sa sigle en anglais) afin de trouver le moyen le plus approprié de présenter l'information, visant à une prise de décisions comptables correcte dans les entreprises du secteur réel, étant donné que ces pratiques sont très bien stipulées au sein des entreprises financières.

\section{Mots clés:}

Dérivés financiers, sous-jacent financier, pleine révélation, sous-jacente énergétique, matières premières. 


\section{Introducción:}

\section{Los instrumentos derivados financieros}

El primer establecimiento de una bolsa de derivados se realizó en Chicago, Illinois, donde se desarrollaban los intercambios de mercancías presentes y de mercancías futuras (commodities). Luego se hicieron contratos llamados forwards donde se pactaba formalmente este tipo de intercambio de inventarios futuros que inicialmente se plantearon como garantías de préstamos. En 1865 los contratos se formalizaron y en 1885 ya se realizaban compras y ventas a nivel mundial (Gonzáles, 2003). Inicialmente, los derivados financieros fueron emitidos por la Chicago Mercantile Exchange siendo los primeros instrumentos de manejo de riesgos que dieron comienzo a los derivados financieros (Gonzáles, 2003). Como se puede ver, los instrumentos financieros existen desde hace mucho tiempo y empiezan con el intercambio de inventarios para el consumo humano y evolucionan hasta convertirse en instrumentos financieros negociados en una bolsa de valores.

Siems (1996, p. 25) afirma que "el mercado de instrumentos financieros ha sido cada vez más amplio en Estados Unidos, Europa y América Latina debido al crecimiento volátil, desregulación del mercado y la aplicación de tecnologías", indicando que el crecimiento económico se asocia al alto movimiento de capital, lo cual lleva implícito ciertos riesgos que afectan a los inversionistas pudiendo ocasionar grandes pérdidas.

Tiempo después se implementan los derivados en Colombia y las normas que los regulan. Dichas normas permiten mitigar los riesgos de pérdidas elevadas. Dentro de las entidades que realizan la labor de regulación se encuentra la Cámara Central de Riesgo de Contraparte que se encarga de recaudar los recursos provenientes de este tipo de negociaciones y entregarlos a los agentes correspondientes; por otra parte, la Superintendencia Financiera se encarga de verificar que las negociaciones se realicen legalmente y que cuenten con los documentos y soportes necesarios. 
El instrumento que se va analizar es el de los derivados financieros. Definidos como contratos cuyo valor depende de los precios de un título, mercancía, tasa de interés, tipo cambiario u otro subyacente ${ }^{2}$; los más transados son los swaps, futuros y opciones. (Diems, 1996). Debido a que en un principio los derivados dependían de la variación de los precios de los activos subyacentes e inicialmente se contaba con pocos de estos activos, el mercado no implicaba un riesgo muy alto, era relativamente fácil de controlar por parte de los entes reguladores. En los últimos años se ha incrementado no solo el número sino la complejidad de las operaciones con derivados, generando la necesidad de utilizar herramientas de control mucho más sofisticadas que involucran también la producción de nuevos elementos de información contable.

Los derivados también pueden definirse como productos financieros contingentes o de especulación, cuyo valor depende de un activo denominado activo subyacente y se realiza por medio de un contrato de compra o de venta a una fecha futura y a un precio determinado (Bolsa de Valores de Colombia, 2012). Este concepto es muy acertado, puesto que existen agentes que de forma especulativa realizan estos negocios para generar utilidades, y otros que son utilizados de forma contingente para mantener el precio negociado del subyacente en el futuro. Los derivados son un instrumento financiero con el cual los inversionistas pueden utilizar los excesos de liquidez, obteniendo rentabilidades. Este tipo de activos tienen altos riesgos, debido a que su valor depende directamente del subyacente (activo que le da el valor del derivado), que regularmente se encuentra en un mercado inestable.

Como podemos ver, el derivado depende completamente de la variación del valor del subyacente para hacer más visible de lo que es un subyacente (ver figura 1).

2 Activo que se pueda medir fiablemente que genere variación en su precio. 
Figura 1. Tipos de subyacentes

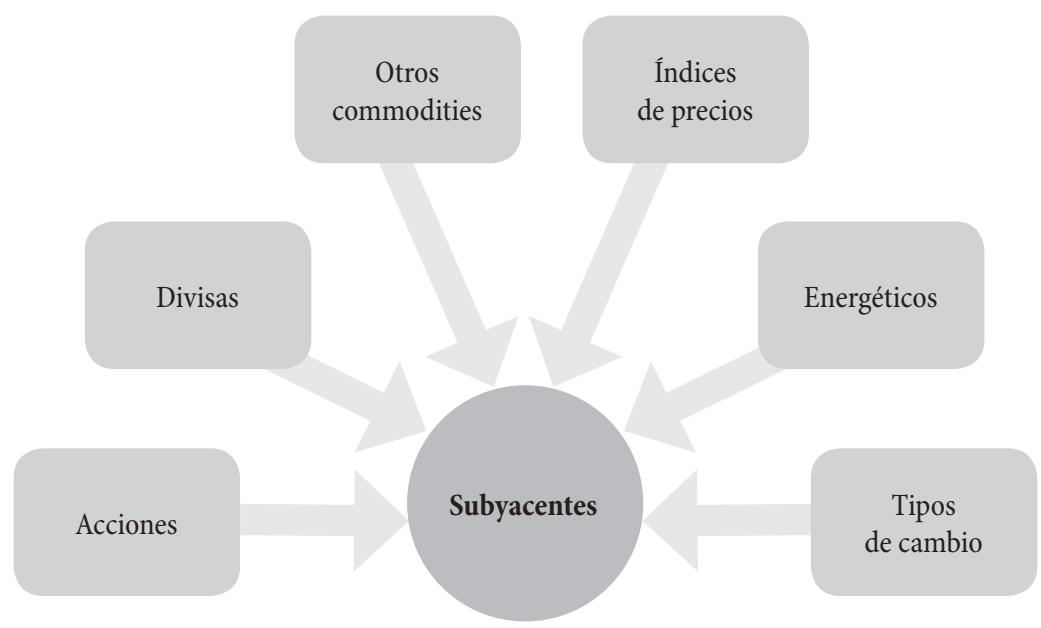

Fuente: elaboración propia.

Tabla 1. Características del instrumento derivado financiero

Como primera medida para realizar el negocio se debe elaborar un contrato entre los agentes participantes, en el que se estipulen el valor de la compra, la fecha en la que se adquiere y en la que se cumple, la forma de pago, etc.

El contrato se da entre dos agentes, el agente comprador y el agente vendedor.

Se compra o se vende una cantidad específica de un determinado subyacente.

El cumplimiento se da en una fecha futura.

En el contrato se debe fijar el precio, la fecha de entrega y la modalidad de entrega.

La inversión inicial no siempre debe ser por el valor total del instrumento financiero.

En algunos tipos de contrato se debe girar cierta cantidad de recursos en garantía

El contrato se liquida en espera a una respuesta en los cambios del mercado financiero. 
El valor inicial que pacten las partes del derivado financiero varía dependiendo de:

-Tipo de interés

-Precio del instrumento financiero

-Precio de materias primas cotizadas

-Según el tipo de cambio

-Índice de precios

-Calificación o índice de carácter crediticio

-Variable no financiera (subyacente)

El valor del contrato se acuerda en la fecha del pacto y su cumplimiento se da en una fecha futura.

La compra y venta de instrumentos derivados financieros en Colombia se debe realizar con un intermediario financiero, ya que la superintendencia financiera así lo exige.

La entrega del derivado se puede hacer en efectivo, especie o liquidación de diferencias.

Se requiere que los derivados se registren en el balance a valor razonable, preferiblemente, a valor de mercado.

Las pérdidas o ganancias que no hayan sido realizadas se deben registrar en el balance sin importar que el derivado no haya sido pagado o ya se haya cumplido. (Sthepen, pp. 269-270)

Fuente: elaboración propia basada en SFAS $\mathrm{N}^{\circ} 133^{3}$.

\section{Tipos de agentes que participan en la negociación del contrato de derivados}

Los agentes son los participantes activos en el contrato de derivados financieros, de ellos existen tres tipos:

a. Agentes de cobertura: son los integrantes de los contratos de derivados financieros que actúan como parte o contraparte con la finalidad

3 Statement of Financial Accounting Standards (SFAS) No 133 de 1998, emitida por la Financial Accounting Standards Board (FASB). 
de mitigar los riesgos en que pueden incurrir, ya sea por pérdida de valor en el futuro o por variaciones en los índices de precios en el mercado.

b. Agentes de especulación: son los participantes de los contratos de derivados financieros que asumen riesgos al adquirir contratos a un valor y esperar a que el subyacente en el futuro se valorice.

c. Agentes arbitrarios: son los que vigilan el negocio e imponen las reglas. En el caso colombiano son la Bolsa de valores de Colombia y la Superintendencia Financiera.

El tipo de agente se identifica por la necesidad de liquidez. La finalidad de un agente de especulación es obtener dinero adicional y la del agente de cobertura es mantener constante su efectivo.

Tabla 2. Tipos de derivados financieros, clasificados por tipo de operación

\begin{tabular}{cll}
\hline $\begin{array}{c}\text { Tipo de } \\
\text { derivado }\end{array}$ & \multicolumn{1}{c}{ Característica } & \multicolumn{1}{c}{$\begin{array}{c}\text { Forma de } \\
\text { liquidación }\end{array}$} \\
\hline & $\begin{array}{l}\text { Este contrato es realizado por justo } \\
\text { acuerdo entre dos partes en búsqueda de } \\
\text { satisfacer sus necesidades de inversión. }\end{array}$ & $\begin{array}{l}\text { a. } \\
\text { Los participantes del contrato deben } \\
\text { entrega física del } \\
\text { subyacente. }\end{array}$ \\
& $\begin{array}{l}\text { b. } \\
\text { llegar a acordar criterios de negociación, } \\
\text { como la fecha de operación inicial, la de } \\
\text { contra un índice } \\
\text { Fomplimiento y el tipo de subyacente a }\end{array}$ & $\begin{array}{l}\text { (entregando el } \\
\text { remanente del } \\
\text { valor). }\end{array}$ \\
& negociar. & c. $\begin{array}{l}\text { Cumplimiento } \\
\text { financiero }\end{array}$ \\
& $\begin{array}{l}\text { Puesto que este instrumento financiero } \\
\text { no tiene muchas regulaciones, no es } \\
\text { necesario realizar el pago inicial ni el } \\
\text { final del subyacente. Solo se realiza si las }\end{array}$ & subyacente en \\
partes los acuerdan. & efectivo a valor de \\
& Este tipo de contrato se puede negociar \\
& por fuera de la cámara de riesgos central \\
de contraparte. (Topa, 2011). & \\
\hline
\end{tabular}




\begin{tabular}{|c|c|c|}
\hline $\begin{array}{c}\text { Tipo de } \\
\text { derivado }\end{array}$ & Característica & $\begin{array}{l}\text { Forma de } \\
\text { liquidación }\end{array}$ \\
\hline Futuros & $\begin{array}{l}\text { Los futuros son muy parecidos a los } \\
\text { forwards, lo único que los diferencia es } \\
\text { que tienen más restricciones y están más } \\
\text { regulados por las leyes que estipulan } \\
\text { los agentes arbitrarios (La BVC y la } \\
\text { superintendencia financiera). Las normas } \\
\text { indican límites de precios, clases de } \\
\text { subyacentes, fechas prudentes, entre } \\
\text { otros. (Topa, 2011). }\end{array}$ & $\begin{array}{l}\text { La particularidad } \\
\text { de esta clase de } \\
\text { derivados es que no } \\
\text { solo pueden ser en } \\
\text { dinero, sino que se } \\
\text { puede hacer entrega } \\
\text { del subyacente. }\end{array}$ \\
\hline $\begin{array}{l}\text { Opciones } \\
\text { (Call - Put) }\end{array}$ & $\begin{array}{l}\text { Son contratos que establecen para } \\
\text { el comprador un derecho pero no la } \\
\text { obligación de venta del subyacente, ya } \\
\text { sea de una opción call o put, a un precio } \\
\text { determinado, las dos partes deben } \\
\text { pactar el precio del ejercicio y la fecha de } \\
\text { cumplimiento. (Topa, 2011). }\end{array}$ & $\begin{array}{l}\text { a. Liquidando } \\
\text { contra un índice } \\
\text { (entregando el } \\
\text { remanente del } \\
\text { valor). } \\
\text { b. Cumplimiento } \\
\text { financiero } \\
\text { (entregando el } \\
\text { subyacente en } \\
\text { efectivo a valor de } \\
\text { mercado). }\end{array}$ \\
\hline $\begin{array}{l}\text { Swap o } \\
\text { permuta } \\
\text { financiera }\end{array}$ & $\begin{array}{l}\text { En este tipo de contrato las dos partes } \\
\text { acuerdan intercambiar flujos de dinero } \\
\text { a una fecha determinada. Se asimila } \\
\text { mucho a los contratos forward. } \\
\text { (Topa, 2011). }\end{array}$ & $\begin{array}{l}\text { Liquidando contra un } \\
\text { índice (entregando el } \\
\text { remanente del valor). }\end{array}$ \\
\hline $\begin{array}{l}\text { Swap sobre } \\
\text { tasa de } \\
\text { interés }\end{array}$ & $\begin{array}{l}\text { Es un contrato donde las dos partes } \\
\text { intercambian pagos o cobros con } \\
\text { diferentes tipos de tasas en la misma } \\
\text { moneda. La obligación de cumplir los } \\
\text { parámetros establecidos es dual. } \\
\text { (Topa, 2011). }\end{array}$ & $\begin{array}{l}\text { Liquidando contra un } \\
\text { índice (entregando el } \\
\text { remanente del valor). }\end{array}$ \\
\hline
\end{tabular}

Fuente: elaboración propia con datos de Topa (2011).

En Colombia la mayoría de contratos de derivados se realizan por medio de la Cámara Central de Riesgo de Contraparte, la cual se encarga de recibir las garantías, utilidades y pérdidas de los derivados, proporcionando un 
medio confiable para realizar este tipo de negociaciones gracias a que se estipulan condiciones equitativas para los participantes. Los derivados también se pueden realizar por fuera de la Cámara, lo cual puede generar riesgos de incumplimiento de pagos y establecer cláusulas menos ventajosas para alguna de las partes. Ningún derivado es completamente seguro, depende de las variaciones que existan en el mercado, los tipos de contratos que se realicen y las necesidades que se tengan como inversionista.

\section{La revelación plena como herramienta contable para la toma de decisiones}

El Decreto 2649 de 1993 habla de las normas básicas que debe cumplir la información contable en Colombia, dentro de estas se encuentra la norma de revelación plena, la cual plantea que todos los entes económicos deben informar completamente, de manera detallada o resumida, las situaciones que afecten directa o indirectamente a la empresa. Esta norma se ve reflejada en los estados financieros de propósito general, notas a los estados financieros y otros informes. Por ejemplo en el estado de resultados, la empresa debe mostrar todos los ingresos, costos y gastos que la afecten, puesto que si se omite alguno, la información financiera estará incompleta y la situación económica no sería real.

Puede que los estados financieros por si solos no les brinden la información necesaria a sus usuarios, por eso las notas a los estados financieros cumplen con la finalidad de explicar detalladamente. Gracias a estas las personas que toman decisiones en la empresa pueden saber al detalle cada dato financiero.

Toda esta información debe ser comprensible, útil y comparable. Si la empresa no cumpla con estas premisas, la información no puede ser utilizada para la toma de decisiones debido a que los estados financieros no son veraces. Adicional a esto, el auditor en su dictamen se encarga de dar fe y comprobar que el principio de revelación plena este siendo cumplido, y no debe permitir que la empresa omita algún tipo de información que la 
afecte. De igual forma, el departamento de control interno da constancia de revelación plena y una de sus herramientas de trabajo es la información contable.

Toda la información que se encuentre en los estados financieros debe ser clara, fidedigna y debe estar completamente soportada para cualquier requerimiento de información de los usuarios finales. No solo basta con realizar estados financieros de calidad, las notas a los estados financieros son base fundamental para que este principio se cumpla.

Después de que la información contable de la entidad se encuentra libre de sesgos y cumple a cabalidad con la norma de revelación plena, es cuando los usuarios de la información pueden tomar decisiones de una forma segura. Existen diferentes maneras en las que las entidades pueden tomar decisiones, una de ellas es el afán de generar utilidades, por lo cual la empresa ignora riesgos con el fin de aumentar el nivel patrimonial. Por otro lado, existen las entidades que tienen un pensamiento mucho más conservador y lo que buscan es generar utilidades teniendo en cuenta variables que pueden afectar estas decisiones.

\section{Generalidades en las inversiones en empresas del sector real}

No solamente las entidades financieras tienen inversiones con diferentes instrumentos financieros. Las empresas del sector real también manejan este tipo de productos. La normatividad contable colombiana no especifica una forma para este tipo de inversión, sobre todo en las empresas del sector real, a diferencia del sector financiero que tiene una gran ventaja en este aspecto.

Normalmente las empresas del sector real no perciben la importancia del registro de este instrumento financiero, debido a que solamente registran el resultado de la inversión al momento del cumplimiento. En otras palabras, solo registran la utilidad o la pérdida, lo que es conocido como 
contabilidad de caja. Al llevar la contabilidad así, se afecta la norma de revelación plena puesto que se está omitiendo información importante que en este análisis, es la de registrar la operación desde el inicio del pacto de la inversión y el registro de las variaciones que se pueden presentar a lo largo de la vida del derivado, por ende, obstaculiza la toma de decisiones porque el administrador puede estar dejando de lado esta información y solamente se da cuenta al momento en que afecta directamente el disponible; por este motivo es importante revisar las diferentes formas de contabilización para que la información contable cumpla con la premisa de la revelación plena.

\section{Contabilización de derivados financieros}

\section{Contabilización general según el Plan Único de Cuentas para comerciantes (Decreto 2650)}

El Plan Único de Cuentas (PUC), menciona las acciones, cuotas o partes de interés social, títulos valores, papeles comerciales o cualquier otro documento negociable que pueden ser de carácter temporal o permanente y se deben reconocer al costo histórico, este reconocimiento implica las valuaciones en cuentas auxiliares adicionales. En el costo histórico hay que reconocer las erogaciones para adquirir la inversión y el efecto de la inflación. Con esta información podemos registrar el derivado financiero como un documento negociable adquirido por el ente económico con carácter temporal, es decir, se debe registrar el derivado financiero como una inversión en el rubro de otros.

Analizando el PUC para comerciantes, existen las siguientes cuentas para registrar las diferentes clases de inversiones (ver figura 2):

La forma más adecuada para el registro de los derivados es la cuenta 1295 "Otras inversiones", ya que ninguna de las otras cuentas se ajusta a las necesidades de este tipo de operaciones. El inconveniente que surge al seleccionar esta cuenta es que según las normas básicas de contabilidad 
del Decreto 2649 (1993) solo se pueden reconocer los hechos económicos realizados, por lo tanto este no es un evento reconocible, ya que no es $100 \%$ cuantificable.

Figura 2. Cuentas contables de inversión

\begin{tabular}{|c|c|}
\hline & $\$$ \\
\hline 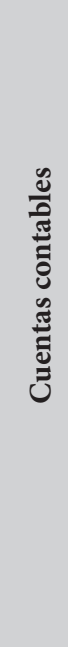 & $\begin{array}{l}\text { • 1.205 Acciones } \\
\text { - 1.210 Cuotas o partes de interes social } \\
\text { - } 1.215 \text { Bonos } \\
\text { - 1.220 Cédulas } \\
\text { - 1.225 Certificados } \\
\text { - 1.230 Papeles comerciales } \\
\text { - 1.235 Títulos } \\
\text { - 1.240 Aceptaciones bancarias o financieras } \\
\text { - 1.245 Derechos fiduciarios } \\
\text { - 1.250 Derechos de recompra (Repos) } \\
\text { - 1.255 Obligatorias } \\
\text { - 1.260 Cuentas en participación } \\
\text { - 1.295 Otras inversiones } \\
\text { - 1.299 Provisiones }\end{array}$ \\
\hline
\end{tabular}

Fuente: elaboración propia con datos del Decreto 2649 de 1993.

Por lo tanto, la contabilización más adecuada según la normatividad colombiana es el registro en las cuentas de orden, exactamente en las cuentas contingentes, que según el Decreto 2649 (1993) en el artículo 42 "reflejan hechos o circunstancias que pueden llegar a afectar la estructura financiera de un ente económico".

Este tipo de inversión puede llegar a afectar la estructura financiera. Si no se selecciona bien el commodity o el tipo de contrato, la empresa puede incurrir en pérdidas que puedan afectar su situación financiera. 
En el ejemplo expuesto en la tabla 3 se puede ver el registro del derecho y la obligación en las cuentas de orden.

Tabla 3. Contabilización del contrato

\begin{tabular}{|c|c|c|}
\hline Contabilización del contrato & Débitos & Créditos \\
\hline 819595 Derechos Contingentes & $\$ 10.000,00$ & $\$$ \\
\hline 84 Derechos Contingentes en contra & $\$$ & $\$ 10.000,00$ \\
\hline
\end{tabular}

Fuente: elaboración propia con datos del Decreto 2650 de 1993.

En este registro se visibiliza que si se registra un futuro por valor de 10.000 , este no afecta directamente el balance ni el estado de resultados, en este momento solamente se ha firmado el contrato financiero.

\section{Contabilización según la Cámara de Riesgo Central de Contraparte de Colombia y la Superintendencia Financiera de Colombia}

La Cámara Central de Contraparte de Colombia fue creada con el objeto de mitigar riesgos con el incumplimiento de los contratos en la compensación de operaciones financieras, entre ellas los derivados. Debido a que el PUC para comerciantes es muy general, la Superintendencia Financiera ha elaborado diferentes documentos para la contabilización de derivados en las empresas del sector financiero con el fin de generar una información clara y detallada para los usuarios de la información. A continuación se explicará, paso a paso, la contabilización general de un derivado financiero según estas dos entidades. 


\section{Registro del derivado cuando el subyacente son acciones, divisas o energéticos}

En la mayoría de las inversiones existe un desembolso inicial que representa la compra y un movimiento al momento de realizar la venta. En la mayor parte de derivados este caso no se observa, puesto que si bien se pacta el valor, solamente se realiza el desembolso de dinero cuando se cumple el derivado y se conoce si el resultado es pérdida o utilidad.

a. Inicialmente el comprador coloca una garantía que respalda el contrato del derivado; esta garantía es en dinero y la estipula la Superintendencia Financiera y depende de que tan alto es el valor del derivado y la Cámara Central de Contrapartes se encarga de realizar el recaudo de los recursos. Esto se realiza cuando la empresa cuenta con exceso de apalancamiento (ver tabla 4).

Tabla 4. Contabilización de la garantía

\begin{tabular}{lll}
\hline \multicolumn{1}{c}{ Contabilización de la garantía } & Débitos & \multicolumn{1}{c}{ Créditos } \\
\hline 1.110 Bancos & $\$$ & $\$ 1.000,00$ \\
\hline 129595 Depósitos de garantía & $\$ 1.000,00$ & $\$$
\end{tabular}

Fuente: elaboración propia con datos del Decreto 2650 de 1993.

b. El comprador adquiere un derecho y una obligación al momento de obtener el contrato, por ende, se debe registrar en las siguientes cuentas de balance (ver tabla 5).

Tabla 5. Contabilización del contrato

\begin{tabular}{lll}
\hline \multicolumn{1}{c}{ Contabilización del contrato } & Débitos & \multicolumn{1}{c}{ Créditos } \\
\hline 129595 Derecho adquirido & $\$ 10.000,00$ & $\$$ \\
\hline 129595 Obligación adquirida & $\$$ & $\$ 10.000,00$ \\
\hline
\end{tabular}

Fuente: elaboración propia con datos del Decreto 2650 de 1993. 
c. La cámara de riesgo central de contraparte realiza los pagos diarios y por lo tanto se deben hacer las respectivas causaciones y registros de la entrada o salida de los recursos. En el caso en el que el derivado se desvalorice se registrará como se observa en la tabla 6 .

Tabla 6. Contabilización de la desvalorización

\begin{tabular}{|c|c|c|}
\hline Contabilización de la desvalorización & Débitos & Créditos \\
\hline 129595 Derecho adquirido & $\$$ & $\$ 200,00$ \\
\hline 129595 Obligación adquirida & $\$ 200,00$ & $\$$ \\
\hline 1110 Bancos & $\$$ & $\$ 200,00$ \\
\hline 5305 Desvalorizaciones de derivados & $\$ 200,00$ & $\$$ \\
\hline
\end{tabular}

Fuente: elaboración propia con datos del Decreto 2650 de 1993.

d. Al momento del cumplimiento del contrato o también llamado Non delivery, se cancelan los derechos y obligaciones obtenidas inicialmente, en este momento no existe movimiento de recursos, ya que la utilidad o pérdida se ha causado diariamente, adicional se cancela el valor de la garantía (ver tabla 7).

Tabla 7. Cumplimiento del contrato

\begin{tabular}{|c|c|c|}
\hline Cumplimiento del contrato & Débitos & Créditos \\
\hline 129595 Derecho adquirido & $\$$ & $\$ 10.300,00$ \\
\hline 129595 Obligación adquirida & $\$ 10.300,00$ & $\$$ \\
\hline 1110 Bancos & $\$ 1.000,00$ & $\$$ \\
\hline 129595 Depósitos en garantía & $\$$ & $\$ 1.000,00$ \\
\hline
\end{tabular}

Fuente: elaboración propia con datos del Decreto 2650 de 1993. 
Cuando el subyacente de un derivado es un TES, debe existir un desembolso de dinero, ya que se negocia directamente con este y el título queda en propiedad del comprador, es decir, que la contabilización sería así:

a. Se hace el registro del contrato en el momento de pactarse, en este tipo de contratos no se realizan garantías debido a que se paga directamente y no existe ningún riesgo de contraparte (ver tabla 8).

Tabla 8. Contabilización del contrato

\begin{tabular}{|c|c|c|}
\hline Contabilización del contrato & Débitos & Créditos \\
\hline 129595 Derecho adquirido & $\$ 10.000,00$ & $\$$ \\
\hline 1110 Bancos & $\$$ & $\$ 10.000,00$ \\
\hline
\end{tabular}

Fuente: elaboración propia con datos del Decreto 2650 de 1993.

b. Igual que los contratos anteriores se debe registrar un derecho y una obligación.

Tabla 9. Contabilización del contrato

\begin{tabular}{|c|c|c|}
\hline Contabilización del contrato & Débitos & Créditos \\
\hline 129595 Derecho adquirido & $\$ 10.000,00$ & $\$$ \\
\hline 129595 Obligación adquirida & $\$$ & $\$ 10.000,00$ \\
\hline
\end{tabular}

Fuente: elaboración propia con datos del Decreto 2650 de 1993.

c. Registro al momento en el que el contrato se desvaloriza (ver tabla 10). 
Tabla 10. Contabilización de la desvalorización

\begin{tabular}{|c|c|c|}
\hline Contabilización de la desvalorización & Débitos & Créditos \\
\hline 129595 Derecho adquirido & $\$$ & $\$ 200,00$ \\
\hline 129595 Obligación adquirida & $\$ 200,00$ & $\$$ \\
\hline 1110 Bancos & $\$$ & $\$ 200,00$ \\
\hline 5305 Desvalorizaciones en derivados & $\$ 200,00$ & $\$$ \\
\hline
\end{tabular}

Fuente: elaboración propia con datos del Decreto 2650 de 1993.

d. Registro al momento en el que el contrato se valoriza (ver tabla 11).

Tabla 11. Contabilización de la valoración

\begin{tabular}{|c|c|c|}
\hline Contabilización de la desvalorización & Débitos & Créditos \\
\hline 129595 Derecho adquirido & $\$ 500,00$ & $\$$ \\
\hline 129595 Obligación adquirida & $\$$ & $\$ 500,00$ \\
\hline 1110 Bancos & $\$ 500,00$ & $\$$ \\
\hline 4210 Ingresos financieros & $\$$ & $\$ 500,00$ \\
\hline
\end{tabular}

Fuente: elaboración propia con datos del Decreto 2650 de 1993.

e. Registro al momento del cumplimiento.

Tabla 12. Cumplimiento del contrato

\begin{tabular}{|c|c|c|}
\hline Cumplimiento del contrato & Débitos & Créditos \\
\hline 129595 Derecho adquirido & $\$$ & $\$ 10.300,00$ \\
\hline 129595 Obligación adquirida & $\$ 10.300,00$ & $\$$ \\
\hline
\end{tabular}

Fuente: elaboración propia con datos del Decreto 2650 de 1993. 
La contabilización según los entes reguladores del mercado es mucho más detallada de la que propone el Decreto 2649 de 1993, pero este procedimiento no es ideal para las empresas del sector real, ya que es demasiado exigente y detallado. Los registros de valoración y desvaloración se deben registrar al finalizar el periodo, puede ser mensualmente.

\section{Contabilización según Normas Internacionales de Contabilidad (NIC)}

Un instrumento financiero es cualquier contrato que dé lugar simultáneamente, a un activo financiero en una entidad y a un pasivo financiero $\mathrm{o}$ a un instrumento de patrimonio en otra entidad (NIC 32) y cumpla estrictamente con los requerimientos establecidos en la tabla 13.

Tabla 13. Características de los derivados financieros

a. El valor del contrato no es fijo, depende de las variaciones del mercado ya sea por tasa de interés, precio de materias primas, índice de precios u otras variables.

b. El precio se pacta dependiendo del tiempo en el que se realice, es decir, si el día uno se pacta un contrato cuyo commodity está en $1,200 \mathrm{u} / \mathrm{m}$ y en el contrato se estipulan 1.000 unidades, este se realizará por $1.200 .000 \mathrm{u} / \mathrm{m}$ dependiendo de las condiciones acordadas.

c. El contrato no requiere de inversión inicial. El tenedor o emisor debe cumplir con la obligación al finalizar el contrato.

d. No es necesario realizar una inversión inicial con capitales demasiado altos para tener rentabilidad. Se debe contar con un respaldo financiero suficiente para cumplir con la pérdida o ganancia que resulte del negocio.

e. El contrato se cumple en una fecha futura.

Fuente: elaboración propia con datos de la Norma Internacional de Contabilidad (NIC) 32.

Para la NIC 32 los Instrumentos Financieros Derivados (IFD) se registran como derecho y obligación para la organización que los adquiere y para los que los venden respectivamente, de este modo el riesgo financiero pasa 
de un lado a otro y cada parte reconoce ambas características del riesgo. En el contrato, cada una de las partes adquiere un derecho o una obligación contractual, que puede ser favorable para una parte y desfavorable para la otra, en la mayoría de contratos. El hecho de registrar los contratos no quiere decir que exista una transferencia de los IFD. La obligación y el derecho se realizan en función a que exista un intercambio (esto quiere decir el intercambio de la utilidad o la pérdida al finalizar la operación) que se pacta al momento de realizar el contrato y es resultado de las variaciones del mercado que se registran a valor razonable.

Los derivados deben ser activos o pasivos financieros. Es decir, no pueden ser instrumentos del patrimonio propio de la empresa de ninguna de las dos partes y están diseñados para dar beneficios financieros futuros, por el contrario, los instrumentos de patrimonio están diseñados para perdurar por más tiempo.

Figura 3. Clasificación del derivado según los elementos de los estados financieros

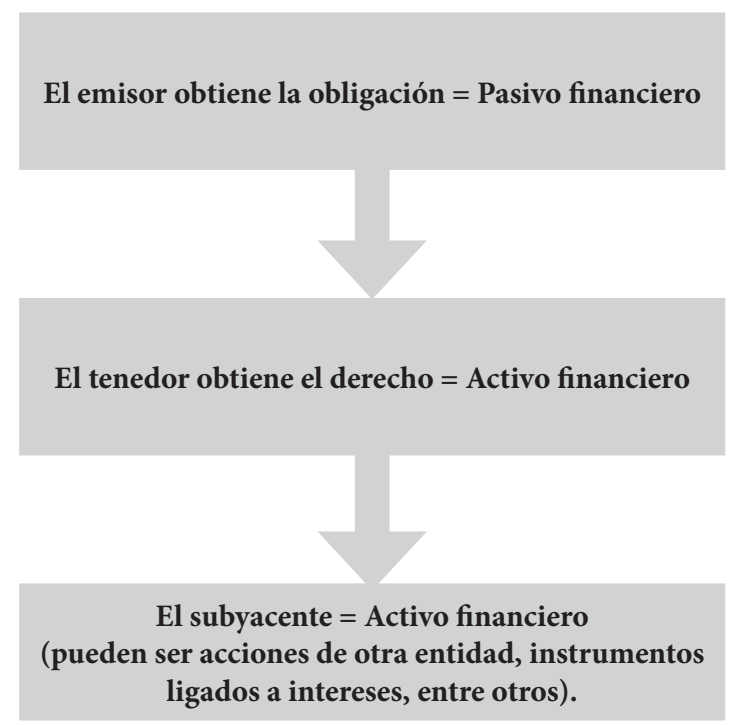

Fuente: elaboración propia con datos de la Norma Internacional de Contabilidad (NIC) 32. 
Según la Norma Internacional de Información Financiera (NIIF), los instrumentos derivados deben agruparse por clases en el balance general, se deben compilar en un solo rubro los instrumentos financieros pero la entidad debe discriminar los diferentes tipos de IFD al momento de realizar o requerir alguna revisión o discriminación.

Los instrumentos financieros son activos o pasivos financieros, por tal motivo se deben mostrar en los estados financieros, en el balance o en las notas. Se deben reflejar a valor razonable con cambios en resultados por separado. Revelar esta información en las notas a los estados financieros implica un ejercicio mucho más detallado y por ende se deben presentar con notas aclaratorias, no solamente con valores monetarios.

La norma habla de registrar la inversión a valor razonable debido a que es el valor que se muestra en el mercado, si se registrara a valor histórico, se registraría a valor nominal y afectaría la información financiera de la empresa, dado que los valores históricos pueden diferir por encima o por debajo del razonable. También se deben reflejar los cambios de los activos y pasivos por movimientos del mercado, ya sea por tipo de interés, precios de materias primas o tipo de cambio en el valor de una divisa.

En la figura 4 se puede apreciar que el comprador adquiere un contrato de derivados por valor de $\$ 1.000 .000$ del cual debe registrar un derecho y una obligación. Inicialmente registra un derecho como un instrumento financiero por este valor y luego registra una obligación de vender el instrumento financiero a futuro. El vendedor realiza el mismo registro que el comprador, debido a que tiene un derecho a comprar el título y una obligación a venderlo. Y por último, dependiendo del resultado del valor razonable del título se registra una ganancia o una pérdida dependiendo sea el caso. 
Figura 4. Ejemplo de contabilización de derivados según Normas Internacionales de Información Financiera (NIIF - IFRS)

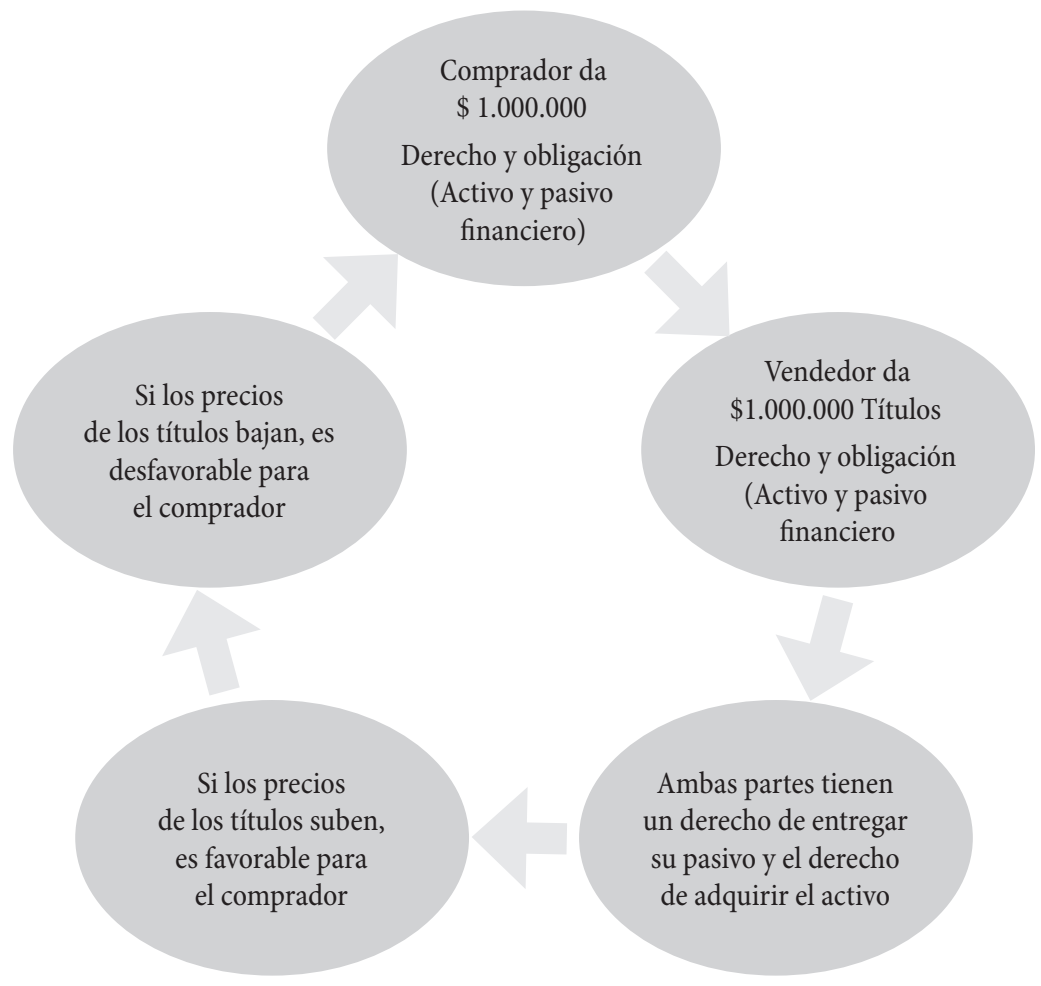

Fuente: elaboración propia con datos de la NIIF 7

\section{Contabilización de derivados financieros según las USGAAP}

Para las USGAAP, y particularmente para la Statement of Financial Accounting Standards (SFAS) 133 de 1998 emitida por la Financial Accounting Standards Board (FASB), no existe una definición exacta de lo que son los derivados. Puntualmente esta norma señala que cualquier valor procedente de algún título valor se le puede dar este apelativo, pero aclara que el derivado debe cumplir con la característica de que del valor 
mínimo de pago se derive uno o varios subyacentes, y al momento de la contabilización recomienda tomar el valor razonable de cada uno de los contratos, como activos y pasivos brutos.

Existen dos tipos de derivados: los de cobertura y los de liquidez. Para poder tomar un derivado como de cobertura debe estar totalmente documentado y se debe aplicar la contabilización de cobertura de valor razonable, la cual indica que las pérdidas o ganancias se registren en el balance y solamente cuando se cumpla el contrato, se deben registrar en el estado de resultados. Los derivados de liquidez se deben registrar bajo la contabilidad de cobertura de flujos de efectivo, la cual indica que las pérdidas y ganancias se registren directamente en las cuentas de resultado, sin registrarlas previamente en el balance.

La principal diferencia que existe entre estos dos tipos de contabilización es que la de valor razonable contempla los riesgos que pueden tener los derivados se registran tanto en el balance como en el estado de resultados y la otra no.

Según el FASB la mejor forma para contabilizar los instrumentos financieros es bajo valor razonable y en este sentido se está avanzando en una armonización de las diferentes normativas internacionales para llegar a este punto (Sthepen, pp. 272-273)

\section{Postura para la contabilización de los derivados financieros}

Debido a que los derivados financieros son un producto volátil y por su naturaleza se ven expuestos a altos y variados riesgos de liquidez, es importante que no solamente la Superintendencia Financiera genere normatividad contable para este fin, sino que adicionalmente el Consejo Técnico de la Contaduría Pública (CTCP) y las demás Superintendencias desarrollen normatividad y regulación en esta materia. Dado que en Colombia cada vez un número mayor de empresas del sector real están invirtiendo en este 
negocio (Pérez, 2012), la postura que en materia contable debe aplicarse es la de observar la forma de registro en los estados financieros, contemplando el principio de la revelación plena y direccionado la toma de decisiones hacia una valoración permanente del riesgo de inversión. De igual manera se sugiere tomar en cuenta el objetivo de la información financiera con propósito general que resalta el marco conceptual de IFRS, donde se visualiza que el objetivo de la misma es el de proporcionar información útil a los inversionistas, prestamistas y otros acreedores para la toma de decisiones (IFRS, 2014) y no solamente como un registro vacío que no interprete plenamente la realidad económica de la transacción.

A continuación se presenta una propuesta de contabilización (registro) de los derivados financieros que tiene como principal ventaja la capacidad de mitigar los riesgos

Como principio, se debe registrar un derecho y una obligación, en el sentido que se ha resaltado a lo largo del documento de que la entidad que firma el contrato tiene tanto derechos como obligaciones en la suscripción del IFD (ver tabla 14).

Tabla 14. Contabilización del contrato

\begin{tabular}{lll}
\hline \multicolumn{1}{c}{ Contabilización del contrato } & Débitos & \multicolumn{1}{c}{ Créditos } \\
\hline 129595 Derecho adquirido & $\$ 10.000,00$ & $\$$ \\
\hline 129595 Obligación adquirida & $\$$ & $\$ 10.000,00$ \\
\hline
\end{tabular}

Fuente: elaboración propia.

Las valoraciones que registre el subyacente durante el período del contrato se deben sumar al valor inicial y se registra el derecho, la obligación y el resultado de la pérdida o utilidad se registra normalmente.

Las utilidades o pérdidas del contrato se liquidan diariamente, pero la comisionista de bolsa compensa el resultado del negocio al cliente al finalizar, debido a que sería un desgaste operativo girarle al cliente todos los días. 
Tabla 15. Cumplimiento del contrato

\begin{tabular}{|c|c|c|}
\hline Cumplimiento del contrato & Débitos & Créditos \\
\hline 129595 Derecho adquirido & $\$$ & $\$ 10.300,00$ \\
\hline 129595 Obligación adquirida & $\$ 10.300,00$ & $\$$ \\
\hline 1110 Bancos & $\$$ & 300,00 \\
\hline 4210 Ingresos financieros & 300,00 & $\$$ \\
\hline
\end{tabular}

Fuente: elaboración propia.

En cuanto a la causación del resultado de la operación es importante aclarar que el Artículo 6 del Decreto 1797 de 2008 emitido por el Ministerio de Hacienda y Crédito Público señala:

ARTÍCULO $6^{\circ}$. Causación del ingreso en las operaciones sobre derivados. En las operaciones sobre derivados, los ingresos respectivos se entienden percibidos en el momento del vencimiento de cada contrato.

Para efectos tributarios se entiende que un contrato agrupa todas las operaciones realizadas bajo una misma tipología contractual (forward, futuro, opción, etc.), por un mismo contribuyente, sobre un mismo subyacente y con una misma fecha de vencimiento. Igualmente, en caso de que el contribuyente realice operaciones que produzcan como resultado el cierre de su posición en el respectivo contrato, el ingreso correspondiente se entiende causado hasta tanto ocurra el vencimiento del respectivo contrato.

Por lo tanto la utilidad de los derivados se debe registrar en el momento del cumplimiento del instrumento financiero, es decir, si un contrato se estipula el día de hoy y se cumple en el término de cuatro meses, la causación de la utilidad o de la pérdida se debe registrar al finalizar este tiempo.

Para aclarar la idea expuesta, se muestra a continuación un ejemplo comparativo entra las formas de contabilización actual de las empresas que invierten en IDF y la contabilización recomendada: 
El día 1 de enero de 2012 la empresa No. 1 adquiere un contrato de derivados cuyo subyacente son acciones de Bancolombia por un valor de 20.000 unidades monetarias, a la empresa No. 2 por medio de una comisionista de bolsa, el término de cumplimiento de la operación es tres meses y se suscribe por un valor de 25.000 unidades monetarias.

Tabla 16. Comparativo de contabilización

\begin{tabular}{|c|c|c|c|c|c|c|c|}
\hline $\begin{array}{l}\text { Cumplimiento } \\
\text { del contrato }\end{array}$ & Débitos & Créditos & $\begin{array}{l}\text { Contabilización } \\
\text { del contrato }\end{array}$ & \multicolumn{2}{|c|}{ Débitos } & \multicolumn{2}{|c|}{ Créditos } \\
\hline $\begin{array}{l}129595 \\
\text { Derecho } \\
\text { adquirido }\end{array}$ & $\$ 20.000,00$ & $\$$ & $\begin{array}{l}819595 \\
\text { Derecho de } \\
\text { contingentes }\end{array}$ & \multicolumn{2}{|c|}{$\$ 20.000,00$} & $\$$ & - \\
\hline $\begin{array}{l}129595 \\
\text { Obligación } \\
\text { adquirida }\end{array}$ & $\$$ & $\$ 20.000,00$ & $\begin{array}{l}84 \\
\text { Derecho de } \\
\text { contingentes } \\
\text { en contra }\end{array}$ & \multicolumn{2}{|l|}{$\$$} & \multicolumn{2}{|c|}{$\$ 20.000,00$} \\
\hline $\begin{array}{c}\text { Contabilización } \\
\text { de la } \\
\text { desvalorización }\end{array}$ & Débitos & Créditos & $\begin{array}{l}\text { Contabilización } \\
\text { del contrato }\end{array}$ & \multicolumn{2}{|c|}{ Débitos } & \multicolumn{2}{|c|}{ Créditos } \\
\hline $\begin{array}{l}129595 \\
\text { Derecho } \\
\text { adquirido }\end{array}$ & $\$$ & $\$ 25.000,00$ & $\begin{array}{l}1110 \\
\text { Bancos }\end{array}$ & \multicolumn{2}{|c|}{$\$ 10.300,00$} & \multicolumn{2}{|l|}{$\$$} \\
\hline $\begin{array}{l}129595 \\
\text { Obligación } \\
\text { adquirida }\end{array}$ & $\$ 25.000,00$ & $\$$ & $\begin{array}{l}5305 \\
\text { Desvalori- } \\
\text { zaciones en } \\
\text { derivados }\end{array}$ & $\$$ & - & $\$$ & 300,00 \\
\hline $\begin{array}{l}1110 \\
\text { Bancos }\end{array}$ & $\$$ & $\$ 5.000,00$ & $\begin{array}{l}819595 \\
\text { Derecho de } \\
\text { contingentes }\end{array}$ & $\$$ & 300,00 & $\$$ & - \\
\hline $\begin{array}{l}5305 \\
\text { Desvalori- } \\
\text { zaciones en } \\
\text { derivados }\end{array}$ & $\$ 5.000,00$ & $\$$ & $\begin{array}{l}84 \\
\text { Derecho de } \\
\text { contingentes en } \\
\text { contra }\end{array}$ & $\$$ & 300,00 & $\$$ & - \\
\hline
\end{tabular}

Fuente: elaboración propia con datos del decreto 2650 de 1993 y las NIIF. 
En la dinámica de contabilización actual se observa que ni la compra ni la venta se ven reflejadas directamente en el balance, sino en cuentas de orden, estas cuentas no reflejan claramente la situación económica de una empresa. En la dinámica de registro recomendada, tanto la compra como la venta se registran en cuentas del activo y se puede observar claramente el derecho y la obligación adquirida y su impacto en la dinámica financiera de la organización.

\section{Conclusiones}

En la normatividad actual existen muchos vacíos referente al tratamiento contable de derivados financieros, esto se debe fundamentalmente a que este tipo de operaciones no se comportan de la misma forma que la mayoría de inversiones, en la medida en que no implican un giro de recursos que equivalga al valor del contrato, sino por la utilidad o pérdida que generará a futuro, en las fechas pactadas para el vencimiento de la operación.

Por tanto, las operaciones con IFD no se pueden registrar contablemente de la forma convencional, en donde es usual reconocer la inversión inicial y el activo se cancela al momento del vencimiento así como las utilidades y las pérdidas obtenidas. Sin embargo, las prácticas de registro son variadas: los contadores más cautelosos registran el valor de los contratos de derivados en las respectivas cuentas de orden, las USGAAP señalan que la contabilización debe verse reflejada solamente al momento de la realización de la utilidad o la pérdida del contrato, tratamiento que es muy parecido al de la actual normatividad colombiana con la diferencia de que esta última especifica que la información contable debe diferenciar los derivados de liquidez de los de cobertura.

Por tanto ninguna de los dos tratamientos informa plenamente en los estados financieros el impacto de los IFD puesto que no se reflejan las variaciones que pueden llegar a tener los subyacentes del contrato durante su vigencia. De tal manera, para que el inversionista o usuario de la información pueda tener claro a qué riesgo está expuesto no es suficiente con 
reconocer la utilidad al finalizar el contrato ni tampoco basta con reconocer en las cuentas de orden el valor de la inversión, el análisis efectuado en este documento indica que la forma más eficiente de reconocimiento de operaciones con IFD, es la que propuesta en el marco de IFRS, el cual indica que se debe registrar un derecho y una obligación, y de manera simultánea se deben realizar las valorizaciones de los subyacentes en cada periodo contable, afectando la cuenta activa y la cuenta pasiva.

Este tratamiento permite la obtención de una información actualizada y basada en la realidad, con lo cual se satisfacen las necesidades de los acreedores, inversionistas y demás usuarios de la información financiera y en general, se garantiza al público una revelación más fiel de los impactos financieros de las operaciones con derivados. 


\section{Referencias bibliográficas}

Bolsa de Valores de Colombia. (2012). Mercado de derivados Estandarizados. Recuperado de http://www.bvc.com.co/pps/tibco/portalbvc/Home/Mercados/ descripciongeneral/derivados

Cámara de Riesgo Central de Contraparte de Colombia S. A. (2010). Dinámica contable futuros compensados y liquidados en la CRCC S. A. Recuperado de http:// www2.camaraderiesgo.com.co/index.php?option=com_docman\&task $=$ doc_ download\&gid=413\&Itemid=40Fradique, C. (2008). Introducción a los derivados financieros. Recuperado de http://www.amvcolombia.org.co/attachments/ data/20081110120040.pdf

Gonzáles, I. (2003). Contabilidad internacional. México: Mcgraw-Hill.

International Accounting Standards Board. (2012) NIF 7. Instrumentos financieros información a revelar. Inglaterra.

. NIC 39. Instrumentos financieros, reconocimiento y valoración. Inglaterra.

. (2014). International Financial Report Standards Framework. Recuperado de http://eifrs.iasb.org/eifrs/bnstandards/es/2012/Framework.pdf

Lawrence D.S., Haley, C. (1983). Administración financiera. Santiago de Chile. McGraw-Hill.

Méndez, C. (2014). Guía del mercado de valores. Recuperado de http://bu.com.co/ sites/default/files/documentos/guia-del-mercado-de-valores.pdf

Ministerio del Interior y de Justicia. (2008). Decreto 1797. Publicado en el Diario Oficial 46998 de mayo 23 de 2000.

Pérez, S. (2012). Empresas del sector real impulsaron las emisiones de renta fija en el mercado. Recuperado de www.larepublica.com.co

Presidencia de la República, Ministerio de Hacienda y Crédito Público. (1993). Decreto 2649. Publicado en el Diario Oficial 41156 de diciembre 29 de 1993. Cartagena, Colombia.

. (1993). Decreto 2650. Cartagena, Colombia.

Siems, T. (1996). Los derivados financieros: ¿se justifican nuevas regulaciones? En Boletín del CEMLA, enero - febrero, 1996, Vol 42.

Superintendencia Financiera Colombia. (2010). Circular externa 004 (2010). Bogotá Colombia. Recuperado de https://www.superfinanciera.gov.co/desc 
168 ACTIVOS | Miguel Ángel Laverde Sarmiento

argas? com $=$ institucional $\&$ name $=$ pubFile $1000233 \&$ downloadname $=$ cap $18 \mathrm{i}$ nstrumentos.doc

Superintendencia de Sociedades. (2012). Comportamiento de los grupos empresariales del sector real de la economía. Bogotá.

Tobaruela, A. (2010). Presentación e información de estados financieros. Boletín Del CEMLA, octubre - diciembre, 2010. Recuperado de http://www.cemla. org/PDF/boletin/PUB_BOL_LVI04.pdf

Topa, G. (2011). Valoración y contabilización de productos derivados. Presentado en capacitación Asobancaria en valoración y contabilización de productos derivados. 